\title{
perifèria
}

Número 11, desembre 2009

www.periferia.name

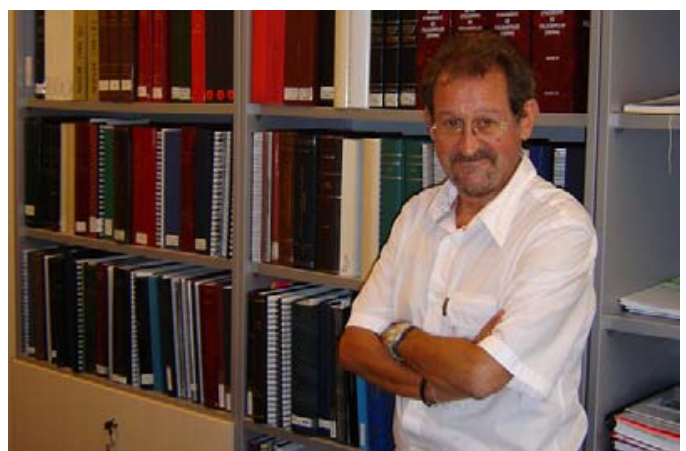

\section{"Jo treballo els meus fantasmes" Entrevista a Joan Prat}

\author{
Gabriel Bosch ${ }^{1}$, Sarah Hoeksma i Laura Pastor \\ Directora: Montserrat Clua i Fainé \\ Universitat Autònoma de Barcelona
}

\section{Resum}

En aquesta ocasió el Projecte Entrevistes ${ }^{2}$ ha sortit més enllà de les parets de la UAB per arribar-se fins a Tarragona, on ha entrevistat el catedràtic recent jubilat de la Universitat Rovira i Virgili, el Dr. Joan Prat. A través de l'agradable conversa que vam mantenir amb ell, el professor Prat ens explicà els seus inicis en l'antropologia, els temes que han marcat la seva trajectòria intel-lectual i la seva visió general de la disciplina. Però paral-lelament, al llarg de la seva biografia apareix també el relat de com foren els inicis de l'antropologia a Catalunya. I més específicament, com es generà i desenvolupà l'actual nucli de potent creació intel-lectual i de recerca antropològica que existeix a la URV.

\footnotetext{
${ }^{1}$ Enviar correspondencia a: Gabriel Bosch, bielbosch@gmail.com

${ }^{2}$ El Projecte Entrevistes és un projecte de recerca i innovació docent creat i dirigit per la Dra. Montserrat Clua i vinculat a l'assignatura Etnologia Regional (Espanya) que imparteix a la UAB. A dia d'avui s'han realitzat 3 entrevistes que es poden consultar a Perifèria ( $n-5, n 07$ i no9). Aquest curs 2008-09, per primera vegada s'han elaborat dues entrevistes simultàniament, la que es presenta aquí feta a Joan Prat, i una altra realitzada a la Dra. Dolores Juliano, que apareixerà en breu publicada a la revista. Per a més informació sobre els objectius i funcionament del projecte, vegeu l'entrevista realitzada a Ramón Valdés (Perifèria, no5).
} 


\section{perifèria}

Número 11, desembre 2009

www.periferia. name

\section{Resumen}

En esta ocasión, el Projecte Entrevistes ${ }^{3}$ se ha desplazado más allá del marco de la UAB para ir hasta Tarragona, donde ha entrevistado al catedrático recién jubilado de la Universitat Rovira i Virgili, el Dr. Joan Prat. En la agradable conversación que mantuvimos con él, el profesor Prat nos explicó sus inicios en la antropología, los temas que han marcado su trayectoria intelectual, y su visión general de la disciplina. Paralelamente al relato biográfico descubrimos también los inicios de la antropología en Cataluña. Y más específicamente, como se generó y desarrolló el actual núcleo de potente creación intelectual y de investigación antropológica que se halla en la URV.

Gabriel - Ens agradaria començar donant-li les gràcies per deixar-se fer aquesta entrevista. Primer de tot perquè és una mica sorpresa. Estem interessats en la història de l'antropologia a Espanya i, com a estudiants i futurs antropòlegs, ens interessa tot aquest tema. Agraïm que ens obri la porta i que ens deixi fer preguntes podent filmar amb càmera i gravadores de veu, fet que sempre fa una mica d'impressió. Moltes gràcies.

J oan Prat - No, a vosaltres.

Sarah - Bé, nosaltres hem dividit la entrevista en quatre parts ja que ens interessa tant el personatge com la disciplina. Vostè està molt vinculat a la història del desenvolupament de l'antropologia a Catalunya. Basant-nos en aquest fet ens agradaria saber de primera mà com es va viure l'esclat de la disciplina des del seu punt de vista.

\footnotetext{
${ }^{3}$ El Projecte Entrevistes es un proyecto de investigación e innovación docente creado y dirigido per la Dra. Montserrat Clua, vinculado a la asignatura Etnología Regional (España) que imparte en la UAB. Hasta hoy se han realizado 3 entrevistas que se poden consultar en Perifèria ( $n^{\circ} 5, n^{\circ} 7$ y no9). Durante el curso 2008-09, por primera vez se han realizado dos entrevistas simultáneamente: la de Joan Prat que presentamos en este número, y otra realizada a la Dra. Dolores Juliano, de próxima publicación en la revista. Para más información sobre los objetivos y funcionamiento del proyecto, ver la entrevista realizada a Ramón Valdés (Perifèria, n5).
} 


\section{perifèria}

Número 11, desembre 2009

www. periferia. name

\section{Comencem fent un repàs a la seva vida i trajectòria. Què el va dur a fer-se antropòleg?}

J - En el meu cas penso que va ser la casualitat. Jo estudiava filosofia, vaig estudiar filosofia a la Universitat de Barcelona del 1965 al 1970 i tenia bons professors de filosofia. I concretament, jo volia ser filòsof. Tenia I'Emilio Lledó, que era un crac de la filosofia grega, sobretot. Després, quan estava a cinquè de carrera, és a dir a l'any 68 o al 69, va arribar el Claudi Esteva, que venia de Mèxic. Ell havia estat exiliat. Es va exiliar durant la guerra, va estudiar antropologia a Mèxic i després, a mitjans dels cinquanta, va tornar primer a Madrid $i$ a finals dels seixanta a Barcelona.

Jo estava a cinquè. Acabava aquell any i tenia tota una sèrie de companys, que després tots vam ser antropòlegs: el Joan Frigolé, el Jesús Contreras,.... Hi havia un altre que després ho va deixar, el Paco Macià.

Em van dir: "Escolta, ha arribat un home de Mèxic que dóna unes classes magnífiques". Les donava a les vuit del matí, vull dir que era una cosa dura anar a les classes a les vuit del matí. Però m'hi vaig matricular. Em vaig matricular a dues assignatures que donava: una introducció a l'antropologia i una sociologia. Allò va ser com descobrir un altre món i vaig dir: "Ostres! això és lo meu".

Va ser, - jo que em dedico a coses de religió -, com una mena de caiguda del cavall, en la comparació antropològica.

El doctor Esteva era un..., és, perquè viu encara ara! És un home molt carismàtic. Donava unes classes esplèndides, cosa que és infreqüent a la universitat que et donin bones classes. I d'altra banda, l'home també estava interessat en formar un primer grup a Barcelona. A tots els que érem de cinquè ens va donar matrícula $\mathrm{i}$ deies: "Ostres, que bo que sóc! [riu] M’han donat matrícula, que bo que sóc".

I després, doncs, primer vaig intentar fer una tesina en filosofia sobre Epicur, però ràpidament vaig demanar una beca per seguir a antropologia. Me la van donar i ja va estar. Vaig preparar primer la tesina i després la tesi en antropologia. Per tant, 


\section{perifèria}

Número 11, desembre 2009

www.periferia. name

és ben bé de la primera fornada. Érem els primers alumnes del Claudi Esteva a Barcelona.

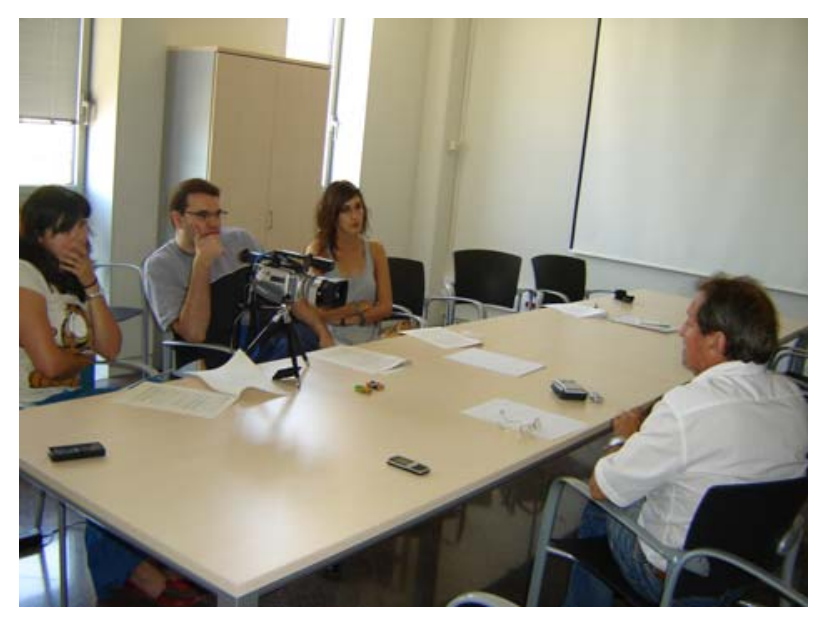

“El doctor Esteva és un home molt carismàtic.

Donava unes classes esplèndides, cosa que és infreqüent a la universitat."

Fotografia: Montserrat Clua

G - Com era fer classes a la Universitat de Barcelona? Com eren les primeres classes d'antropologia que fa el Claudi Esteva? Eren les primeres classes d'antropologia que es feien a Espanya, pràcticament.

J - Sí, sí.

G - Aleshores, clar, com era descobrir una disciplina nova? Com s'introdueix? Com te'n parlen? Qui et diu que serveix d'alguna cosa?

Sí, bé, si servia d'alguna cosa o no en aquells moments això era l'últim que em preguntava. M'agradava i m'hi trobava a gust. [Pensa] L'Esteva s'havia format a Mèxic però $a m b$ els paràmetres de l'antropologia americana. A més a més de l'antropologia social, és prehistòria, és lingüística i és antropologia física o biològica. Ell intentava fer-nos una mica el plantejament, la introducció a l'antropologia cultural amb els paràmetres americans. Després ens va donar vàries assignatures sobre cultura andina, ja que ell era un bon expert treballant les cultures andines. I 


\title{
perifèria
}

Número 11, desembre 2009

www. periferia. name

bé, doncs, ja dic, donant classes era molt bo.

Recordo unes classes sobre els indis americans que semblava que et trobaves allà, en una pel-lícula de cinemascop. Quan t'explicava sobre els comanxes i sobre els hopis era una cosa esplèndida. I bé, doncs, tot una sèrie de gent ens vam enganxar amb això.

Les classes com eren a Barcelona a finals dels seixanta? Doncs home, en general, eren unes classes molt tristes, però no per l'antropologia que va néixer amb molta vitalitat gràcies a l'Esteva.

Suposo que veient-ho a nivell històric l'Esteva va ser el pal de paller de la Universitat de Barcelona. A la mateixa època el Ramón Valdés arribava a l'Autònoma i ell va formar el seu departament allà. I el Carmelo Lisón, doncs, estava a Madrid i hi va formar el seu departament. Eren els tres grups que en aquells moments funcionaven junt amb el de Sevilla, que els sevillans s'havien format també amb l'Esteva amb un curs que ell havia donat en una mena de màster d'aquell temps, que havia donat al Museu d'Etnologia de Madrid.

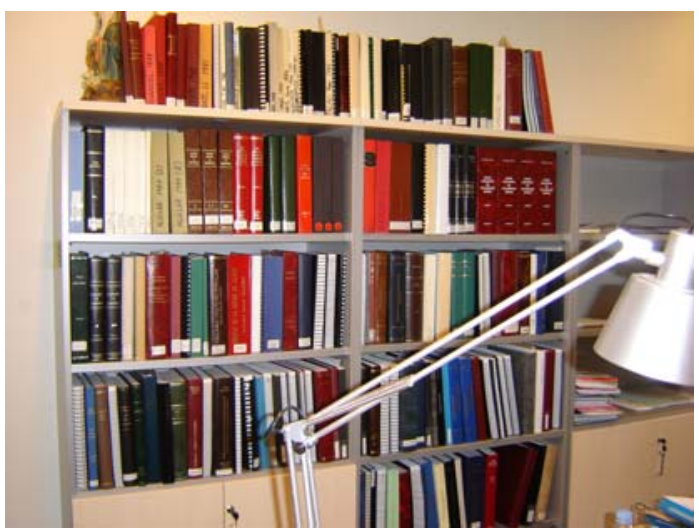

\author{
"A la vida he errat moltes \\ vegades. Del què estic \\ convençut que ho vaig \\ encertar de ple és d'haver- \\ me dedicat a \\ l'antropologia. No m'he \\ penedit ni un moment."
}

Tesis doctorals al despatx del Prof. Prat Fotografia: Montserrat Clua

G - Però, què el feia diferent? En quin moment, estudiants de filosofia, estudiants de sociologia... éreu allà i de cop i volta arriba el moment en 


\section{perifèria}

Número 11, desembre 2009

www. periferia. name

\section{què us convertiu en els primers estudiants de l'antropologia que començava. Quina cosa us va atreure d'allà?}

J - Home, perquè comparat amb la filosofia era una cosa viva i tota la història que no era només estudiar als llibres sinó que havies de veure les societats com funcionaven i tenia un atractiu extraordinari.

A veure, la pregunta també us la podria fer jo a vosaltres, no? Per què us heu dedicat a l'antropologia i no a la filosofia o a la sociologia o a la lingüística? Doncs bé, per què, no sé, hi ha gent a la què la disciplina ens atrapa. Jo en el meu cas penso que a la vida he errat moltes vegades i molts cops que dius: "això hauria pogut fer-ho d'una altra manera". Del què estic convençut que ho vaig encertar de ple és d'haver-me dedicat a l'antropologia perquè, en fi, hi porto trenta anys i escaig. I la veritat és que no m’he penedit ni un moment. És a dir, sempre he gaudit.

\section{S - I com un celranenc acaba fent classes a Tarragona? Com és tot el procés?}

J - Sí, també una altra casualitat. És a dir, jo era becari al departament de Barcelona, estava fent la tesi. Feia una tesi sobre Celrà, que després en tot cas podem parlar una mica sobre el tipus d'estudis que fèiem els primers que ens vam dedicar a aquestes coses, que és clar, donada la impossibilitat d'anar-te'n a l'Equador o a l'Àfrica, doncs estudiaves la teva societat, no? Obligat a fer l'antropologia at home.

Jo era becari a Barcelona i es va introduir aquí a Tarragona l'Antropologia. El que havia de venir era el Joan Frigolé. El Joan Frigolé havia estat molt temps, tot el primer temps a l'Autònoma, és a dir, a la vostra facultat. Però ell estava preparant la seva tesi, que la va fer sobre Calasparra, sobre jornalers agrícoles i tot el món de Calasparra, que és un poble de Múrcia. I em van dir: “Escolta, per què no hi vas tu a Tarragona?". Ostres, però a mi a Tarragona no se m'hi havia perdut res i jo més aviat tenia intenció d'anar-me'n després cap a Girona. “Va, home, prova-ho un any!". I ho vaig provar un any, però ja dic, substituint a en J oan Frigolé que estaria 


\section{perifèria}

Número 11, desembre 2009

www. periferia. name

un any fent treball de camp a Calasparra. Després tornaria cap a Barcelona per arreglar la tesi.

I aquí jo la veritat és que m'hi vaig trobar bé des del començament. I després quan a en Joan Frigolé li feia una mandra terrible al següent any venir cap aquí, em va dir: "Escolta, per què no t'hi quedes tu?". I jo vaig dir bé, doncs ja em va bé perquè m'hi havia trobat a gust des del començament. Anava i venia, ja que vivia a Barcelona. Però bé, va ser un primer any agradable. Donava, al començament, dues assignatures: una Introducció a l'Antropologia Cultural, que la donava no només per a la gent d'història sinó també pels psicòlegs i els pedagogs, vull dir que eren classes molt massives. Però penso que va funcionar bé. I després, ràpidament, al segon any, vaig començar amb l'Etnologia dels Pobles d'Espanya, que en dèiem Etnologia de la Península I bèrica. I em vaig dedicar amb això.

Després donava una altra assignatura a la Universitat de Barcelona i aquí. Fins que hi va haver un moment que em van dir: "Escull: o Barcelona o Tarragona". I a Barcelona en aquells moments, l'ambient del departament no era un ambient agradable. Era una època més o menys conflictiva. El Claudi Esteva funcionava com un catedràtic d'aquells tradicionals. Nosaltres érem joves i no sempre s'acceptaven les directrius del Claudi Esteva, que d'altra banda estimàvem molt. Hi va haver com una mena de... [pensa], d'assassinat del pare, d'un intent d'assassinat del pare. Jo m'hi trobava molt malament, perquè em trobava entre dos focs i vaig dir: “Em quedo a Tarragona que hi estic més tranquil". Al següent any ja va venir el Juanjo Pujadas, després va venir el Josep Maria Comelles, després va venir la Dolors Comas i entre tots quatre ja vam fer un nucli en el qual ens hi dedicàvem molt i més potent. I amb ganes tots de quedar-nos aquí com molt aviat vam fer.

\section{G - Això va ser la gènesi del Departament d'Antropologia a Tarragona.} J - Sí.

\section{G - Com es crea el Departament d'Antropologia a Tarragona?}

J - Com es crea? Bé, el primer any tenia una única assignatura, que era Introducció 


\section{perifèria}

Número 11, desembre 2009

www. periferia. name

a I'Antropologia Cultural. Després I'Etnologia dels pobles d'Espanya o l'Etnologia de la Península I bèrica.

Quan va entrar el Juanjo Pujadas, a l'any següent, va donar una Antropologia Lingüística, sobretot pensant en la gent de lingüística. Quan va venir el J osep Maria Comelles, va introduir la Història de l'Antropologia. Amb la Dolors Comas ho vam reforçar amb l'Antropologia Econòmica i l'Antropologia Política. I es va anar creant, sense existir de facto, una sèrie d'assignatures troncals. I així fins a inicis dels noranta, quan ens vam convertir en independents de Barcelona, ja que fins aquell moment érem de la Universitat de Barcelona i aquí eren les Dependències Universitàries de Tarragona.

Érem un grup ja constituït, relativament sòlid. També hi havia l'Oriol Romaní. Érem cinc persones. Alguns de nosaltres, ja érem catedràtics i en el moment de plantejar que volíem tenir un departament i tenir una llicenciatura, la veritat és que no hi van haver massa problemes. Portàvem ja un rodatge considerable i no hi van haver conflictes per part de les autoritats acadèmiques d'aquell moment.

El què passa és que és clar, sempre hem tingut dos veïns molt poderosos. Que sou l'Autònoma i la Universitat de Barcelona. I després ens hem hagut d'espavilar una mica com hem pogut, sobretot en qüestions de màsters i tercers cicles, que sembla que serà la política que se seguirà a partir d'ara.

\section{S - Vostè va estudiar durant la Dictadura franquista. Com s'estudiava en aquells moments? Va formar part del moviment estudiantil?}

J - Poc, jo poc. Perquè em vaig haver de pagar tota la carrera. A casa em van dir: "nen, si vols estudiar...".

Jo havia estat a Montserrat, a l'Escolania de Montserrat. I a l'Escolania de Montserrat li van dir als meus pares: "feu-lo estudiar perquè el nano serveix, i és estudiós". Però a casa, diners pocs. Un poble de pagès de Girona... El meu pare extraordinàriament treballador no ho era i em van dir: "T'hauràs d'espavilar". I per tant la carrera me la vaig fer tota treballant en un collegi de monges a Santa 


\section{perifèria}

Número 11, desembre 2009

www. periferia. name

Coloma. Jo donava classes de llatí, d'història de l'art, de geografia i del què se'm posés per davant. Amb la qual cosa, la vida intensa estudiantil que portaven alguns dels meus companys (com per exemple el J oan Frigolé, que va estar a la presó o el J esús Contreras, que també era un personatge molt actiu), jo la veritat és que no la vaig tenir. Seguia en certs moments i estava absolutament d'acord amb els plantejaments estudiantils del moment, però la meva capacitat de participar-hi va ser molt escassa. Perquè em passava moltes més hores donant classes de llatí o de francès o d'història de l'art que no pas a la Universitat. Hi anava estrictament per rebre les classes i poca cosa més. És a dir que no m'ho vaig poder permetre.

G - I si seguim fent una mica d'història, quan vostè va començar a conèixer l'antropologia espanyola, com era? Sabem que hi havia algunes persones a Madrid, però es vertebraven, es coneixien, es parlaven...?

J - Sí, al començament, sí. Al començament hi va haver un primer congrés a Sevilla, al 72 o al 73, organitzat diríem pel catedràtic que en aquells moments estava a Sevilla. És la Primera Reunión de Antropólogos Españoles, vull dir és el primer llibre de congressos. El catedràtic de Sevilla era l'Alfredo Jiménez, que era bon amic del Claudi Esteva. En aquells moments era bon amic del Carmelo Lisón i també del Ramon Valdés, i van anar tots a Sevilla.

Després de Sevilla hi va haver un altre congrés. Hi havia molta germanor, és a dir, va ser un congrés on eren molt poca gent, pocs professionals i els altres, que en aquells moments estàvem fent tesines, estàvem fent tesis i escrivint els primers articles. Hi havia molt bon rotllo. Després hi va haver un altre congrés a Segòvia, organitzat pels de Madrid i aquell bon rotllo va continuar. Fins aquell moment, controlat, diríem pels diferents caps: el catedràtic de Madrid, el catedràtic de Sevilla, el catedràtic de Barcelona i ells, diríem, controlaven bé la història. El què passa és que ràpidament Carmelo Lisón no es va trobar a gust amb les trobades aquestes, més o menys massives (que tampoc eren massives, perquè érem poca gent). I es va espavilar pel seu compte. Va muntar la seva pròpia estratègia de fer reunions més tancades, a llocs específics i sobretot a Galícia. I a partir d'aquí, això 


\section{perifèria}

Número 11, desembre 2009

www.periferia.name

va suposar una primera fractura.

I en el Congrés de Barcelona del 77 hi va haver un conflicte generacional important. És a dir, els què en aquells moments érem professors, que ens dèiem "PNNs": Professors No Numeraris. Hi va haver un enfrontament clar amb els capitostos, els que controlaven la història institucional. I aquest enfrontament va ser sobretot a nivell de quins simposis s'havien d'organitzar, a qui s'havia de convidar, a com es gastaven els diners,... Va ser una època com molt moguda. Era ben bé als inicis de la Transició i suposo que tot influïa. Els ànims estaven caldejats, teníem ganes de viure d'una altra manera de la què havíem viscut i és clar, la universitat franquista era una universitat estrictament autoritària on el catedràtic i el cap de departament es regien pel mando y ordeno. I arribava un moment doncs què això era difícil de sostenir. I va ser com una mena de rebel-lió per part del què podríem dir-ne segona generació, que era la generació de la gent que ara tenim seixanta anys.

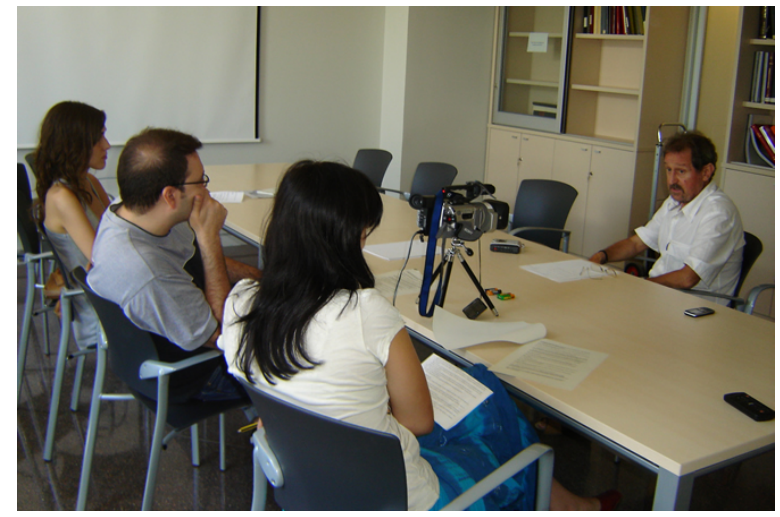

Fotografia: Montserrat Clua

“No hi ha cap antropòleg que hagi estat ministre, ni cap antropòloga que hagi estat ministra. I això és significatiu."

G - Ja hem arribat als 80 . Als anys 80 esclata la disciplina i comencen a haver-hi uns estudis d'antropologia més regulars i es comença a popularitzar l'antropologia. Què va passar en aquell moment en els 80 que 


\section{perifèria}

Número 11, desembre 2009

www. periferia. name

\section{no hagués passat abans? És una cosa que té a veure amb la política? Amb la societat? Té a veure amb que de cop i volta es pot estudiar antropologia a les universitats? Fins al moment era un reducte més tancat...}

J - Sí... A les dictadures antropologia poca. I per tant, durant el franquisme no hi havia la possibilitat d'estudiar ni psicologia ni antropologia, perquè són disciplines que són crítiques i que ajuden a pensar per un mateix i a no seguir determinats models. I l'antropologia, sobretot I'antropologia que es podia fer en els anys 80: antropologia marxista, antropologia ecològica, tota la qüestió de l'estructuralisme... No era allò tan conservador que havia arribat d'Estats Units o d'Anglaterra, i per tant el context afavoria l'emergència d'una nova disciplina que era l'antropologia.

Jo penso que amb l'adveniment de la democràcia qui "es va emportar el gat a l'aigua" va ser la sociologia i sobretot els sociòlegs. Tenien una professió que la van poder fer molt més poderosa ràpidament. Només cal veure els ministres, sobretot els ministres del començament, tant de la UCD com després del socialisme, que havien estat sociòlegs. No hi ha cap antropòleg que hagi estat ministre, ni cap antropòloga que hagi estat ministra. I això és significatiu. I és clar, hi havia tot el món de les eleccions, tot el tema de la preparació d'eleccions, enquestes, etc. I per tant, els sociòlegs van controlar el mercat molt millor del que nosaltres vam fer. Que d'altra banda suposo que aquest és un dels nostres grans problemes: què fem amb l'antropologia.

Inicialment en els anys 80 , a finals dels $70-80$, no hi havia massa problema perquè sortíem pocs llicenciats. No hi havia llicenciatura en antropologia i la gent que s'hi volia dedicar s'hi podia dedicar. I jo recordo que al començament et venien a buscar. Perquè jo donava classes en un col-legi de monges i estava ben cobert, però em van venir a buscar: "escolta, per què no vens $i$ et donarem una beca $i$ podria ser la tesina...". És a dir, que per a tots els que sortíem i en teníem ganes hi havia la possibilitat de dedicar-te a l'antropologia, perquè en definitiva s'estaven generant i s'estaven construint els diferents departaments. En canvi, és clar, després això és com una mena de cul de sac: ara pots tenir estudiants esplèndids 


\section{perifèria}

Número 11, desembre 2009

www. periferia. name

que acaben el doctorat i... La possibilitat de treballar com antropòlegs és molt limitada perquè el mercat és bàsicament un mercat universitari: poc als museus, quelcom encara menys a l'administració, i per tant no hi ha un mercat de treball clar.

Inicialment aquest mercat de treball el donava la mateixa universitat i com que les universitats creixien... Jo recordo al començament: quan jo havia començat al 65 érem molt poca gent que estudiàvem. I a la generació del baby boom, que és una generació dels 80 , la universitat es va omplir, hi havia moltíssima més gent que començava a estudiar. Amb la qual cosa es van crear noves universitats, noves carreres. És la construcció de l'Autònoma, la construcció de determinades facultats a Barcelona... Hi ha un creixement important.

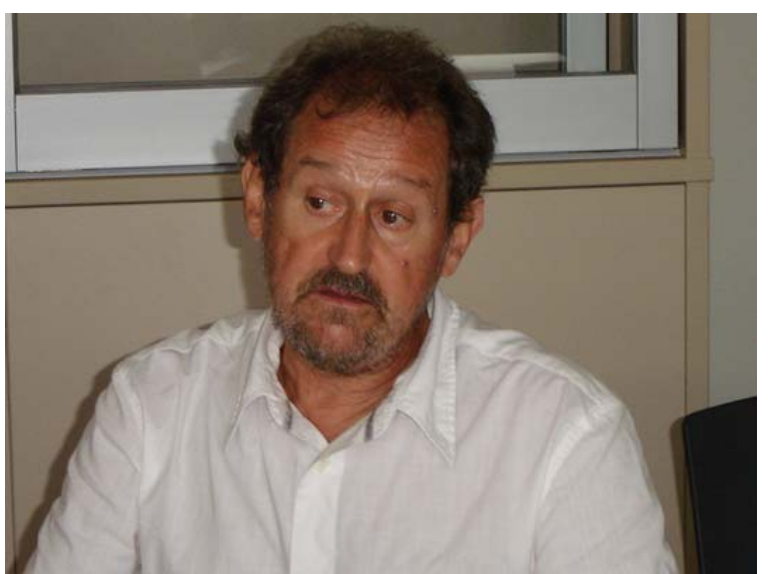

“La possibilitat de treballar com antropòlegs és molt limitada perquè el mercat és bàsicament un mercat universitari."

S - Ara ens agradaria parlar de la seva obra acadèmica i les línies de investigació que ha desenvolupat. Creu que els orígens biogràfics i acadèmics condicionen la perspectiva $i$ el desenvolupament dels estudis? En general i en el seu cas particular.

J - Jo em pensava que no, que un seleccionava les coses doncs perquè m'interessa això i ho treballo. Després, - això és molt personal però penso que ho he de dir -, vaig tenir una època de crisi personal important (no amb l'antropologia però si amb 


\section{perifèria}

Número 11, desembre 2009

www. periferia name

altres àmbits) i em vaig psicoanalitzar. I a les sessions de la psicoanàlisi jo em preguntava: "Per què m'he dedicat al que m'he dedicat?". I I'analista, que era un bon analista, m'ajudava. Quan jo penso en el que m'ha interessat al llarg de la meva vida, és evident que m'he dedicat a estudiar coses que m'atenyen d'una manera molt directa i molt personal. La tesi doctoral, per exemple, la vaig fer sobre el pairalisme gironí. Clar, jo soc d'una família pairal. El meu pare no era hereu, era el fill segon. I el fet d'estudiar el pairalisme significava que jo estava estudiant sense saber-ho els meus propis fantasmes. El com funcionava una família de tres generacions i com aquí, a Catalunya, un determinat fill és el que rebia un tant per cent molt important de l'explotació. I els altres eren els sobrevinguts, eren els cabalers. I els conflictes que això generava... I per tant, en definitiva, el meu primer tema, el meu primer objecte d'estudi que era estudiar la societat pagesa gironina, suposo que era perquè jo era fill de pagès, fill d'una família pairal i propietaris de Celrà, que ja dic que no era de la branca principal sinó d'una branca secundària.

Després em vaig dedicar a estudiar santuaris. Dius: “i per què m'he dedicat a estudiar santuaris?" I és clar: "Has viscut 5 anys en un santuari!" I per tant, doncs, és normal. Però d'això me'n vaig adonar fa 607 anys. I és clar, m'he dedicat a estudiar qüestions de religió moltes vegades: que si l'experiència religiosa ordinària, que si la religiositat popular, que si els santuaris... En fi, els aplecs i totes aquestes històries. I suposo que tot això tenia uns orígens, que jo continuava treballant els meus fantasmes. I ara ja ho accepto com una cosa: que sí, que jo treballo els meus fantasmes. El que passa és que suposo que els artistes ho treballen d'una determinada manera i els antropòlegs ho treballem d'una altra. No sé si això és generalitzable. Jo no vull dir que el que es dedica a l'antropologia econòmica o a l'antropologia política estigui lligat a aspectes econòmics o polítics. No ho sé, en el meu cas sí. Jo m'ho miro ara en perspectiva i clarament els temes que m'han interessat són temes que a nivell vital diríem han tingut rellevància important al llarg de la meva vida. I ara continuo amb el mateix. És a dir, si un dels primers llibres que vaig fer es titulava La mitologia i la seva interpretació, continuo 


\section{perifèria}

Número 11, desembre 2009

www. periferia. name

trenta anys després treballant o ara tornaré a treballar sobre mitologia. I són temes recurrents. Després hi hauria la neura aquesta de les biografies que no ho sé... Per què sempre $m$ 'he dedicat a fer biografies? No ho sé. Suposo perquè tinc un temperament com molt obsessiu, allò del detall...[riu].

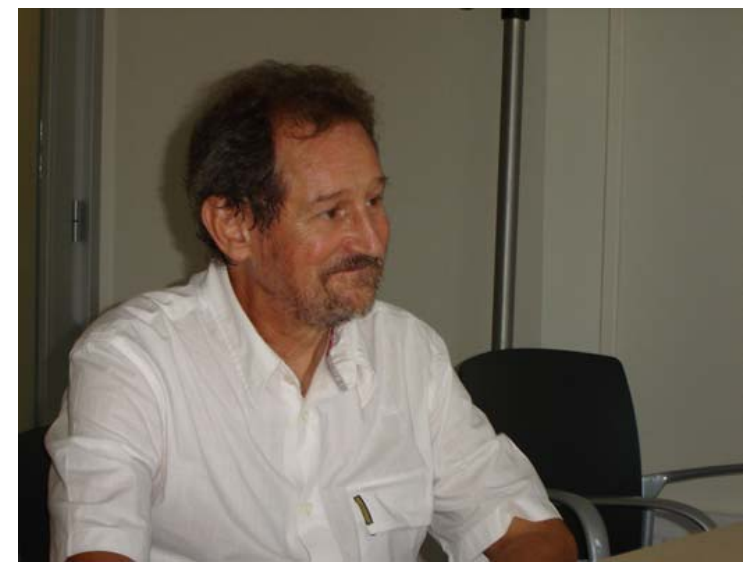

Fotografía: Montserrat Clua

“Quan jo penso en el que m'ha interessat al llarg de la meva vida, és evident que $m$ 'he dedicat a estudiar coses que m'atenyen d'una manera molt directa i molt personal (...) Jo treballo els meus fantasmes."

\section{S - I pel que fa a la història a l'antropologia? Perquè vostè és un especialista...}

J - Sí, però una història molt limitada. La història de l'antropologia a Catalunya o la història del folklore. I tot això també estaria relacionat amb buscar pares fundadors, jo diria. És clar, segons les classes del Claudi Esteva per nosaltres el pare fundador era Malinowski, o era Radcliffe-Brown, o eren els antropòlegs americans. Però mai ens va parlar de l'existència d'un Violant i Simorra o d'un Aureli Capmany, que eren els que aquí havien fet d'etnògrafs. Normalment etnògrafs aficionats, però alguns amb una certa professionalitat i un bon fer. No diré el cas de l'Amades, que és el més conegut però era més barroer a I'hora de 


\section{perifèria}

Número 11, desembre 2009

www. periferia. name

treballar. I suposo que a finals dels $70 \mathrm{i}$ inicis dels 80 buscàvem pares que no fossin el Malinowski sinó pares més propers. I això va ser el què a mi em va portar a indagar sobre tota la qüestió de l'etnografia o el folklore del S. XIX, que tenia tot aquest to també nacionalista (que en aquells moments això també es vivia d'una manera molt intensa en els inicis dels 80 ). Hi havien tota una sèrie d'elements que estaven relacionats i buscaves pares fundadors més propers.

Tot això penso que molt relacionat amb la fundació de l'Institut Català l'Antropologia i les primeres conferències que es van fer. A mi em van fer l'encàrrec d'una d'elles que parlés dels antecedents de l'antropologia aquí a Catalunya. I era això, doncs, veure què havia passat a la segona meitat del s. XIX fins a l'arribada de l'Esteva a Catalunya. I veure una mica quins eren els grans folkloristes i alguns pocs etnògrafs que hi havia. I això és el que em va portar doncs a llegir-los sistemàticament. I després vam fer un Ilibre amb el Llorenç Prats (que després ell va ser el que va continuar amb aquest tema, junt a la Dolors Llopart) que era això: una història del folklore a Catalunya.

I d'aquí vaig saltar a Espanya... Però que jo, d'història de l'antropologia en general, en sé poca. Altres companys, per exemple en Comelles, en saben molt més... Jo controlo més a nivell d'Espanya. O controlava. Però els experts en història de l'antropologia són d'altres, aquí en el departament.

\section{G - Ja que estem parlant de història de l'antropologia a Espanya... Quines creu que són les figures més rellevants d'aquesta història? Quins són els autors que li han cridat l'atenció?}

J - Home ara hauria de revisar.. Els primers andalusos, els Machado: el Machado i Núñez i el Machado i Álvarez tenen una obra... Sobretot el Machado i Álvarez (que era el pare dels poetes), un home molt potent que seria l'introductor del folklore a Espanya. Després havia llegit amb molt entusiasme als bascos, sobretot al Barandiarán. Per tota la qüestió del nacionalisme i com el folklore és viscut sobretot en el nord de la península Ibèrica: a Galícia, el País Basc i a Catalunya. Penso que 


\section{perifèria}

Número 11, desembre 2009

www. periferia. name

hi ha unes connexions amb el nacionalisme claríssimes. Un Vicente Risco, per exemple. És un dels grans etnògrafs gallecs, i al mateix temps era un dels grans polítics gallecs regionalistes o nacionalistes. Al meu entendre, l'obra del pare Barandiarán és un intent de comprovar la doctrina nacionalista del Sabino Arana: "els bascos som diferents de tots els altres, tenim unes característiques físiques diferents, tenim una llengua diferent, els altres ens estimen poc...", i això, si vas seguint la obra del pare Barandiarán, es veu. De la mateixa manera que en el cas català hi ha un Batista i Roca en els anys 10, o el grup l'Arxiu d'Etnografia i Folklore de Catalunya que es crea a la universitat de Barcelona. També penso que bàsicament és un intent de comprovar les teories del Prat de la Riba sobra la nacionalitat catalana. Penso que hi ha una relació intensa en aquest sentit i aquests autors en un determinat moment em van interessar molt. En canvi, els altres grups que hi podia haver a Madrid, que hi podia haver a Canàries (tots ells de final del XIX i inicis del XX), o que hi podia haver a Sevilla, és més un discurs sobre I'home en general, reflexionant sobre els homes. I en canvi al nord, als llocs on el regionalisme i el nacionalisme aflora en el XIX, és més el caràcter aquest folklòric. Hi ha un llibre que el vam fer entre varis, es titula Antropología de los Pueblos de España, on hi ha una introducció on intento explicar aquestes coses. I va ser molt, molt criticada, però en fi... Intentava representar els dos diferents eixos d'antropologia espanyola i, sobretot, les seves diferenciacions. I potser em vaig passar a l'hora de marcar les diferències entre gallecs, bascos i catalans respecte d'andalusos, canaris i madrilenys (que són els sis grans llocs on hi havia hagut un folklore o una etnografia potent).

\section{S - I quins creu que han estat els autors oblidats? Hi ha autors oblidats?}

J- Oblidats? Ai, potser sí, ... però no se m'havia ocorregut mai de... Clar, segurament sí que n'hi deuen d'haver. Bé, un que tenia fama de ser una autor maleït era el González de Velasco, fundador del Museu Etnològic de Madrid. Però més que per ser un personatge oblidat, era perquè va tenir una vida molt tràgica $\mathrm{i}$ es considerava que la seva ànima continuava tombant, hi ha tota una història d'apareguts... Era un personatge que era viscut com un fantasma i que feia una 


\section{perifèria}

Número 11, desembre 2009

www. periferia. name

certa por. Però és cert que hi deuen haver autors oblidats. De totes maneres jo penso que amb el temps s'han anat estudiant alguns dels grans autors a nivell històric. I és clar, suposo que sí que en deuen quedar per estudiar. Però els canaris han treballat amb força l'antropologia canària. Els andalusos durant una època van fer tota una sèrie de tesis doctorals intentant esbrinar la història del folklore i de l'etnografia d'Andalusia. Aquí a Catalunya també ho vam fer, Galícia també ho han fet, i a Madrid també la Carmen Ortiz va treballar tot el que seria l'antropologia madrilenya.

G - Abans ha passat molt per sobre d'un tema que també volíem tractar i és que no li ha atret mai fer treball de camp a fora? Aquesta visió romàntica del treball de camp a una societat allunyada molt estranya... Això pel que sabem tampoc ho va desenvolupar, no li ha atret o és que les circumstàncies són així?

J - Hi va haver la possibilitat, quan vaig acabar, d'anar a fer treball de camp a Guatemala. Començo des del començament. Si tu estudiaves antropologia a Anglaterra o estudiaves antropologia a França, o estudiaves antropologia als Estats Units, el ritus de pas que havies de fer era anar-te'n a una societat exòtica i fer un treball de camp, doncs, com il faut: estar-te el temps que pertoqués fent-lo i ja està. I la immensa majoria dels antropòlegs d'aquestes nacionalitats, porten darrere un treball de camp intens en els 'pobles primitius', els 'pobles exòtics'.

Quan a nosaltres se'ns va plantejar la possibilitat de fer les tesis doctorals, normalment els treballs de camp eren el primer pas per fer la tesi doctoral. Però per a nosaltres la possibilitat d'anar-te'n a fora era molt remota. Aquí no t'ho pagava ningú i havies de tenir un padrí que et mantingués durant un any a l'Àfrica o allà on fos. I això, en aquells moments en què el sistema de beques era pràcticament inexistent, doncs era molt complicat. Hi van haver alguns col-legues a Barcelona que sí que van marxar fora. Com que el Claudi Esteva en aquells moments tenia un projecte al Perú es va endur com a col·laboradors a gent, com per exemple al Jesús Contreras. El Jesús Contreras va fer la seva tesi doctoral 


\section{perifèria}

Número 11, desembre 2009

www. periferia. name

sobre Chinchero al Perú i tota la temàtica de la societat pagesa andina. Després hi van anar també I'Ignasi Terradas, que era un dels membres més joves del grup i segurament el més brillant de tots nosaltres. A ell li va resultar bé. A mi em va sortir la possibilitat d'anar-me'n a Guatemala, però bàsicament era per posar ordre a la biblioteca d'un potentat guatemalenc que era enginyer de no sé què. Era francès i necessitava algú que li posés ordre a la biblioteca. I jo vaig pensar: “Home, podria anar allà, amb el que em pagui això em permetrà sobreviure una llarga temporada a Guatemala". Però després, per tota una sèrie de raons personals... Vivia amb una companya que em va dir: “Jo, a Guatemala no se m'hi ha perdut res. I per tant, si tu te n'hi vas, la història s'ha acabat". I jo en aquells moments estava a gust i vaig dir: "Doncs escolta, estudiaré Celrà, que és més a prop...". I després, doncs, ja entres dins de la rutina aquesta.

Després amb el Jesús Contreras vam anar a fer un treball que no es va publicar mai sobre artesania peruana que és el meu únic contacte, diríem, amb indígenes. Però ja no hi he tornat mai més. I sí que penso que... Però més aviat el que m'agradaria ara és anar-me'n, no sé, a un monestir budista i passar-hi mig any o vuit mesos. Més que no pas fer la típica monografia que, per una altra banda, ja no està de moda. Però sí que poder-me'n anar a l'Índia, o poder-me'n anar al Nepal, o a un monestir budista, em faria il/lusió. I ara que em prejubilo, doncs, potser serà el moment.

\section{S - Però vostè ja ha treballat sobre monestirs, centres... Vol dir que el què li agradaria és anar a la India per fer treball de camp?}

J - Sí, per a fer treball de camp, sí. Per mi els temes, quan hi penso, calculo que em duren uns 7 anys. Vull dir l'interès pels temes, pels objectes d'estudi. I després els temes ja se'm fan pesats, em fa la sensació que torno sempre sobre el mateix i canvio. Són canvis relatius... Al començament em vaig interessar per les qüestions de pairalisme i mitologia, aproximadament em va durar 7 anys. Després em vaig dedicar a festes i cultura popular, va durar 7 anys més: santuaris marians i experiència religiosa ordinària, que seria tots els aspectes religiosos convencionals, 


\section{perifèria}

Número 11, desembre 2009

www. periferia. name

folklòrics i populars. I després, no sé per què, (quan em vaig psicoanalitzar ho vaig treballar poc, suposo) em vaig dedicar a les sectes, que també em va durar uns 7 anys. I després em vaig dedicar al mètode biogràfic que van ser 7 anys més. I ara, que espero que em duri 7 anys el que ara estic fent. Però el que vull dir és que sembla un número màgic per a mi el 7 , o un número simbòlic. No sé exactament perquè, però tinc això: quan miro el que he fet són aproximadament 7 anys. I després n'acabo fins els nassos del què estic fent i procuro no tornar-ho a fer perquè m'avorreix. I penso que per treballar has d'estar apassionat pel que fas perquè si no, malament rai.
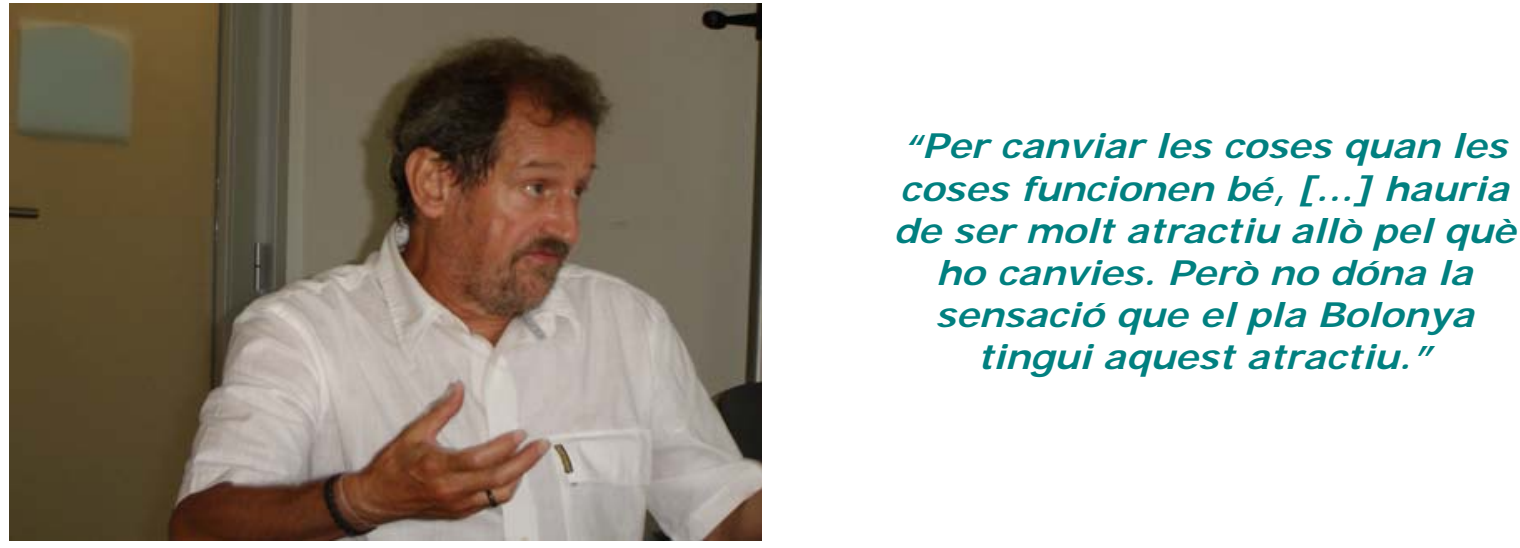

“Per canviar les coses quan les coses funcionen bé, [...] hauria de ser molt atractiu allò pel què ho canvies. Però no dóna la sensació que el pla Bolonya tingui aquest atractiu."

Fotografia: Montserrat Clua

\section{G- Ens interessa la seva visió sobre l'antropologia avui, com està la} disciplina. Una cosa que hem de preguntar és que li sembla el pla Bolonya.

J - Sí... El que passa és que, donades les meves previsions de que jo ja no viuré el pla Bolonya amb la intensitat que he viscut el món acadèmic fins ara, sempre me I'he mirat en certa manera "des de la barrera". I com que penso que a tots els departaments se n'ha parlat moltísim, crec que són la gent jove, els professors joves, els que han de decidir si Bolonya sí, o Bolonya no, o com ens ho muntem. I jo ja..., és una cosa que ja us ho fareu. Jo ja no ho viuré i per tant, .... doncs no m'hi poso. I cada vegada la cosa ha funcionat més en aquest sentit, d'un cert 


\section{perifèria}

Número 11, desembre 2009

www. periferia. name

desinterès. Jo sé que la meva vida a la universitat és una vida que ara canviarà d'una manera molt clara. I com us deia jo el pla Bolonya ja no el viuré.

És clar, a mi el que em preocupa de tot el que ha suposat el pla Bolonya és que jo penso que teníem una llicenciatura (no només vosaltres - UAB-, sinó la gent de la Universitat Central, la gent de Madrid...), una llicenciatura que funcionava bé i hi havia uns doctorats que funcionaven bé. I és clar, canviar les coses quan les coses funcionen bé, ... hauria de ser molt atractiu allò pel què ho canvies. Però no dóna la sensació que el pla Bolonya tingui aquest atractiu com perquè t'atrapi. En absolut. Però ja dic, en ser una cosa que m'afecta poc a nivell personal i professional, doncs jo ja no ho he viscut. Això suposo que també deu ser un tema molt personal, perquè hi ha gent de la meva generació que ho viu amb molta intensitat i lluiten i se'n preocupen, però no ha estat el meu cas.

\section{S - Aquí a Tarragona tenen pensat fer el grau o es centraran en el màster?}

J - Encara hi ha debat sobre si es farà grau o no es farà. $\mathrm{Hi}$ ha gent que es partidària de fer-ne. Hi ha altra gent que no en són i aposten per reforçar més tota la qüestió del tercer cicle, que sembla que es allà on nosaltres podem sobreviure millor. Però no sé. Aquí hi ha hagut un canvi generacional important que a l'Autònoma també I'heu tingut... Els caps de departament fins ara havíem estat els iaios, vull dir la gent gran. I vam anar passant-hi tots. I ara per primera vegada el cap de departament es el Jordi Roca, que deu tenir la quarantena i és ex-alumne nostre. I en fi, hi ha una mena de pacte tàcit per part de la gent de la meva generació, dels que estem als 50 llargs o els 60, de dir: "Escolta, el futur és vostre. Qui us ho heu de muntar i, per tant, qui heu de discutir si us interessa el grau o no, sou vosaltres". Jo si em diuen que haig de donar classe per un màster, doncs ho faré amb molt de gust. I si ho he de fer en un grau, amb molt de gust també. Però és clar, per mi serà només una assignatura. I el futur professional se I'han de dissenyar ells com puguin. Perquè vull dir que prou ordenada avui esta la cosa des de fora.

G - Si tornem a parlar de l'antropologia a Tarragona, sempre ha estat un 


\section{perifèria}

Número 11, desembre 2009

www. periferia. name

\section{nucli potent. Com explicaria a algú de fora, com per exemple nosaltres, com ha estat sempre un nucli tan actiu acadèmicament?}

J - No ho sé. Moltes vegades això ens ho hem preguntat i ens ho hem demanat. Tarragona és una ciutat molt provinciana, molt tancada, però al mateix temps a nivell d'universitat ens van deixar la màniga molt ampla de que ens ho muntéssim com poguéssim i com volguéssim. I així com en altres departaments, per exemple, els nuclis fundadors es van barallar entre ells i els conflictes personals van ser intensos, aquí no. Al menys els cinc primers: primer vaig ser jo en arribar. Després el Juanjo Pujadas, el Josep Maria Comelles, la Dolors Comas i l'Oriol Romaní, que som els cinc més grans. Vam tenir molt bona sintonia els cinc, i això des de sempre. Evidentment hi ha hagut friccions, friccions notables, però sempre vam tenir clar que hi havia una política de departament que passava per sobre dels nostres propis interessos. La qual cosa ens va donar molta força perquè quan calia discutir una cosa el que miràvem era això, la política d'estat, la política del departament. I el que anàvem era a defensar una estratègia conjunta. En canvi, pel que conec i pel que he vist, això no ha estat una cosa comuna sinó que en altres departaments la gent s'ha barallat entre ells, cadascú ha fet la guerra pel seu compte i això, és clar, resta forces. I això és una de les coses que per exemple, la gent jove d'ara diu: "És que nosaltres no tenim la unió que teníeu vosaltres". I potser això sí que és cert. A més, jo penso que a nivell professional i vocacional tots ho hem sentit d'una manera molt intensa, ho hem viscut molt. Vull dir que ens ho hem passat molt bé fent antropologia i gestionant el que hem pogut gestionar del departament. I això amb els veïns poderosos que tenim, que sou vosaltres, la gent de Barcelona!

\section{S - Es consideren una antropologia perifèrica dintre de l'antropologia perifèrica que es l'espanyola?}

J - Nosaltres... segurament som perifèrics. El què passa és que hi ha un parell de grans temes, com són l'antropologia de la medicina o l'antropologia urbana, que jo penso que aquí no és perifèrica sinó que és molt central. Hi ha gent que hi ha 


\section{perifèria}

Número 11, desembre 2009

www. periferia. name

treballat molt, que són els big masters de les temàtiques aquestes.

G - Hi ha l'I nstitut Català d'Antropologia i aquí a Tarragona tenen l'I nstitut Tarragonès d'Antropologia... Són contradictoris, són complementaris? Vostè que ho coneix bé, com ens ho explicaria?

J - Inicialment es va crear I'Institut Català d'Antropologia, del qual tota la gent d'aquí en va formar part i en som socis fundadors. L'objectiu de crear I'Institut Català d'Antropologia era de tenir un marge de maniobra per fer coses fora del control de la Universitat, poder muntar seminaris amb la gent que nosaltres convidàvem, poder fer una sèrie de xerrades que dintre de la universitat, com que manaven uns altres, era molt més complicat. I en certa manera va ser una institució para-universitària perquè la immensa majoria de professors joves d'aquells moments de la universitat, tant de l'Autònoma com de la Central, eren membres de l'Institut Català d'Antropologia i funcionava bàsicament a Barcelona. El que passa és que després dels inicis dels 80 aquí estàvem relativament ben establerts i vam dir: "Per què no fundem una branca de I'Institut Català d'Antropologia que es dirà Institut Tarragonès d'Antropologia?". Però la casa mare continuava sent l'Institut Català d'Antropologia.

Així hem funcionat durant molts anys. El que passa és que hi havia tota una sèrie de problemes de tipus molt primari, molt materials. Que si anaves aquí a la Diputació a demanar ajut per muntar unes jornades i ens demanaven el N.I.F.; resultava que era d'una institució de Barcelona... O tu anaves a demanar amb I'Institut Tarragonès d'Antropologia a l'Ajuntament i ens deien: “Escolta, vosaltres pertanyeu a un grup que té la seu a Barcelona". I ens dificultava molt el funcionament quotidià. D'una altra banda hi va haver petits conflictes d'enteniment amb la direcció de I'ICA i vam decidir que fundàvem I'ITA, Institut Tarragonès d'Antropologia. En aquests moments la intenció és de treballar conjuntament, però legalment és una institució independent.

S - S'està gestant un Col-legi Professional d'Antropologia, i segons ens explicava l'altre dia la María Valdés en una xerrada que es va fer a 


\section{perifèria}

Número 11, desembre 2009

www. periferia. name

l'Autònoma, s'està gestant el col-legi estatal i l'autonòmic. Vostè en té informació, té algun tipus d'opinió respecte això?

J - No, perquè no he anat a cap reunió i la informació que tinc es de quarta mà, és a dir del nostre representant que va a les reunions aquestes. La veritat és que no.

\section{S - Però és necessari un col-legi professional?}

J - Home, jo penso que sí... La Montse Clua segurament us en pot parlar amb més coneixement de causa que jo, perquè a nivell institucional, per utilitzar una paraula poc acadèmica, hem anat molt putejats. I penso que dintre de les comissions estatals no hi ha antropòlegs, que quan demanem trams ens avaluen avaluadors que no tenen ni idea del que es l'antropologia. Sempre seríem la minyona i la parenta pobra de tota una sèrie d'altres disciplines. I és clar, una de les maneres de sortir d'aquest estat de marginació jo crec que seria el col-legi professional. Sé que la María Valdés hi ha deixat les banyes pel col-legi professional, però ja dic, és una altra de les coses aquestes que ja ni me l'he plantejada. Bé, abans no sé si us ho he comentat o no, però a la Montse Clua sí: jo em prejubilo l'1 de setembre i escolta'm... Un col·legi professional per a un jubilat... A veure, me n'alegraré pels joves que vinguin, però a mi ja..., poca cosa. Ara al que em voldria dedicar els darrers anys és a les coses de la professió i d'investigació que realment m'interessen. I les reunions deixar-les pels que són més joves i tenen més força per resistir-les que no pas jo.

“La disciplina antropològica projecta una mirada especial sobre les societats humanes i sobre els esdeveniments, propera i Ilunyana. I penso que són poques les disciplines que tenen aquesta mirada específica i especial."

G - Ara ja només dues preguntes per acabar, una mica més generals sobre l'antropologia... Què creu que és el que l'antropologia pot aportar a la societat d'avui? Què la fa diferent de les altres ciències socials? Per què és necessària? 


\section{perifèria}

Número 11, desembre 2009

www. periferia. name

J - Home, jo penso que ( $\mathrm{i}$ això ja us ho hauran explicat $\mathrm{i}$ vosaltres ho haureu pogut comprovar a partir d'haver estudiat antropologia), hi ha una mirada especial, que la disciplina antropològica projecta una mirada especial sobre les societats humanes i sobre els esdeveniments. Seria allò que deia Lévi-Strauss: que al mateix temps és una mirada molt propera (perquè fem treball de camp i escoltem a la gent, i un dels elements més importants de l'antropologia és la capacitat d'escolta), i al mateix temps una mirada més llunyana que és la mirada més teòrica. I penso que són poques les disciplines que tenen aquesta mirada específica i especial. I que aquesta mirada específica i especial pot ser una mirada crítica. És que jo n'estic molt convençut que la mirada antropològica és molt millor que altres mirades, però dóna la sensació que, per exemple a nivell polític o econòmic, té ben poca transcendència perquè se'ns té poc en compte.

\section{S - I per acabar, doncs, si ens pogués dir dues coses bones i dues coses dolentes de ser antropòleg, o una i una...}

J - Dolenta, la veritat és que no ho sé... Jo m’ho he passat molt bé sent antropòleg, i espero continuar passant-m'ho molt bé. I va ser això: com una mena d'enamorament a primera vista. I com us deia abans, de coses a la vida que n'estigui realment satisfet n'hi ha ben poques. I en canvi aquesta seria una d'elles, la professió, que les circumstàncies de la vida m'hi va portar. Perquè jo als 21 anys, quan vaig acabar la carrera, no tindria ni idea del que era l'antropologia si no m'hagués matriculat per casualitat a una assignatura d'Introducció a I'Antropologia cultural. I ara seria professor d'institut, suposo, de filosofia o del que fos. I a mi la veritat és que m'ha donat moltes, moltes satisfaccions.

I alguna cosa desagradable... Home, jo potser per ser un antropòleg complet em faltaria allò que apuntàvem abans: d'haver viscut, jo què sé, un any o un any i mig a l'Àfrica o al Sud-est asiàtic o a l'Índia. I és una cosa que no he fet mai i que ja no sé si faré. I que penso que això ha de donar una perspectiva molt diferent. La gent de les nostres generacions en aquell moment que, per exemple, eren d'Estats Units o d'Anglaterra, ens venien a estudiar a nosaltres. Serien totes aquestes 


\section{perifèria}

Número 11, desembre 2009

www. periferia. name

monografies que hi ha dels anys 70 i dels anys 80 . I és clar, els primitius i els exòtics no només eren els africans, sinó els espanyols, junt amb els italians, els grecs i els turcs, doncs érem objectes d'estudi. Hi ha algunes bones monografies d'aquestes de l'època. I és clar, aquesta és una experiència que jo no he tingut mai, estudiar en un país diferent al meu. I això suposo que, com que no ho he tingut, no sé que m'hauria suposat a nivell vital, però suposo que hauria estat una cosa important. I que per ser un antropòleg fet i acabat doncs, això és el que em falta. Però bé, no es pot tenir tot...

\section{G - Espero que no ens haguem fet molt pesats...}

J - No, no! Per mi ha estat molt agradable, i m'heu ajudat també a rememorar tota una sèrie de coses que sense les vostres preguntes segurament tampoc ho hauria fet.

\section{- Moltes gràcies.}

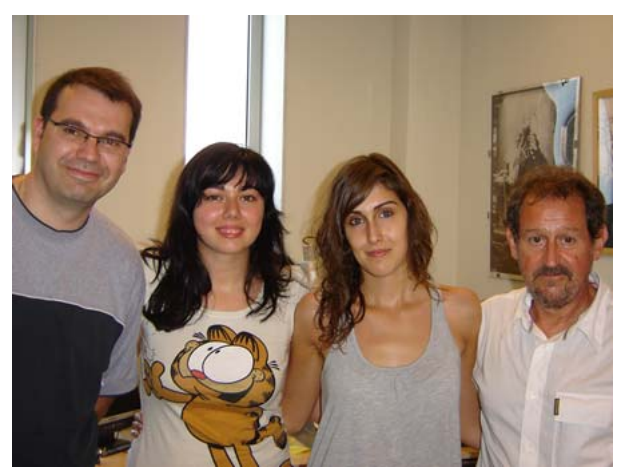

D'esquerra a dreta: Gabriel Bosch, Sarah Hoeksma, Laura Pastor i Joan Prat Fotografia: Montserrat Clua 